\title{
PACLITAXEL GELATIN NANOPARTICLES FOR INTRAVESICAL BLADDER CANCER THERAPY
}

\author{
Ze Lu ${ }^{1}$, Teng-Kuang Yeh ${ }^{1}$, Jie Wang ${ }^{1}$, Ling Chen ${ }^{1}$, Greg Lyness ${ }^{1}$, Yan Xin ${ }^{1}$, M. Guillaume \\ Wientjes $^{2}$, Valerie Bergdall ${ }^{3}$, Guillermo Couto $^{3}$, Francisco Alvarez-Berger ${ }^{3}$, Carrie E. \\ Kosarek $^{3}$, and Jessie L-S. Au ${ }^{2}$ \\ ${ }^{1}$ Optimum Therapeutics, LLC. 1381 Kinnear Road, Suite 111, Columbus, OH 43212 \\ ${ }^{2}$ College of Pharmacy, The Ohio State University, 496 W.12 ${ }^{\text {th }}$ Avenue, Columbus, OH 43210 \\ ${ }^{3}$ College of Veterinary Medicine, The Ohio State University, 1900 Coffey Road, Columbus, OH \\ 43210
}

\begin{abstract}
Purpose-We have shown that inadequate drug delivery to tumor cells is a major cause of failures in intravesical therapy of nonmuscle-invading bladder cancer. This is partly due to the dilution of drug concentration by urine production during treatment. To address this problem, we developed gelatin nanoparticles of paclitaxel (PNP) designed to yield constant drug concentrations. The hypothesis that constant, therapeutic concentrations in urine, bladder tissue and tumors can be attained was evaluated in dogs.
\end{abstract}

Materials and methods-We studied the drug release from PNP in culture medium in vitro. In vivo studies were performed in tumor-free dogs and in pet dogs with naturally occurring transitional cell carcinoma, where the pharmacokinetics (plasma, urine and tumors) of PNP was determined.

Results-The release of paclitaxel from PNP in vitro and in vivo was rate-limited by the drug solubility in aqueous medium. This property yielded constant drug concentrations independent of changes in the urine volume over the 2-hr treatment. Intravesical PNP showed low systemic absorption and favorable bladder tissue/tumor targeting and retention properties, with pharmacologically active concentrations retained in tumors for at least 1 week.

Conclusions-The constant drug release from PNP may overcome the problem of drug dilution by newly produced urine and the sustained drug levels in tumors may reduce the treatment frequency.

\section{Keywords}

Intravesical chemotherapy; bladder cancer; transitional cell carcinoma; gelatin nanoparticles; paclitaxel

\section{INTRODUCTION}

Patients presenting with nonmuscle-invading tumors (i.e., Ta tumors located in the urothelium, T1 tumors located in the lamina propria, and/or carcinoma in situ Tis) are

Address correspondence to Jessie L.-S. Au, College of Pharmacy, The Ohio State University, 496 W.12 $2^{\text {th }}$ Avenue, Columbus, OH 43210. Telephone: (614)292-3494. Fax: (614) 688-3223. au.1@ osu.edu.

Some of the results were presented at the 2008 Surgical Urology Oncology Annual Meeting and at the 2009 American Urological Association Annual Meeting. 
typically managed by transurethral tumor resection, plus neoadjuvant or adjuvant intravesical immunotherapy or chemotherapy ${ }^{1}$. The most commonly used agents are Bacillus Calmette-Guérin (BCG) and mitomycin C (MMC). We have identified inadequate drug delivery and chemoresistance as the two major causes for the highly variable and incomplete response of intravesical therapy in patients. Our data further indicate that a major source in the variability of drug exposure (and hence variable treatment efficacy) is due to the dilution of the instilled drug by residual urine and newly produced urine ${ }^{2-4}$.

American Urological Association recommends adjuvant intravesical treatment as standard of care for high risk patients. However, a recent study based on the SEER database shows that only $42 \%$ of eligible patients receive intravesical therapy ${ }^{5}$; the authors' conclusion that overcoming the under-utilization is a priority is echoed by others ${ }^{6}$. The potential reasons of the under-utilization include inconvenience due to the multiple weekly treatments, the required pharmacokinetic interventions such as dehydration and ultrasound-guided bladder emptying, and the unfamiliarity or difficulty with dose administration.

We propose that the problems of inadequate drug delivery, chemoresistance, and underutilization of intravesical therapy may be overcome by using chemotherapeutics that (a) have equal or greater activity than MMC, (b) penetrate bladder tissues better than MMC, (c) require less frequent treatments, and (d) are easy to administer (e.g., without exhaustive bladder emptying or patient dehydration). We identified paclitaxel as a candidate since it shows higher activity against human bladder cancer cells ${ }^{7}$, and produced a $42 \%$ response in advanced and/or metastatic bladder cancer in a phase II trial ${ }^{8}$. In addition, paclitaxel, due to its lipophilicity, can penetrate the urothelium more readily than MMC ${ }^{9}$. Paclitaxel is tightly bound to intracellular macromolecules such as tubulin and microtubule, resulting in significant drug accumulation (70-1,500 folds) and retention in tumor cells ${ }^{10}$, and thereby offers the possibility of extending the drug action beyond the typical $2 \mathrm{hr}$ treatment duration. Finally, paclitaxel induces apoptosis through p53-dependent and - independent pathways, which, in view of the high frequency of p53 mutations in bladder cancer ${ }^{11}$, is an advantage over agents such as MMC that depend on functional p53 pathways for apoptosis ${ }^{12}$.

Accordingly, we studied the paclitaxel formulation approved for intravenous administration, i.e., paclitaxel dissolved in Cremophor and ethanol; our results show that during intravesical therapy, paclitaxel remains entrapped in Cremophor micelles, which reduces the free drug fraction and consequently lowers the drug penetration into the bladder tissue ${ }^{13}$. We then explored using a surface-active agent dimethyl sulfoxide (DMSO) to disrupt the micelle structure; the results show that while DMSO increased the free drug fraction, it had other counteracting effects (increased urine production and increased drug removal by perfusing capillaries) that reduced the tissue drug concentrations ${ }^{14}$. We eventually developed a new formulation, paclitaxel-loaded gelatin nanoparticles (PNP), that rapidly releases paclitaxel and has activity in vitro, and yields high paclitaxel concentration in bladder tissues in 3 tumor-free dogs in vivo ${ }^{15}$.

The present study evaluated whether intravesical PNP provides constant drug concentrations in urine and yields favorable concentration-time-depth profiles in bladder tissues and tumors. The study was conducted in tumor-free dogs and pet dogs with naturally occurring bladder tumors.

\section{MATERIALS AND METHODS}

\section{Chemicals}

Cephalomannine was obtained from the National Cancer Institute (Bethesda, MD); paclitaxel from Handetech (Houston, TX); high performance liquid chromatography (HPLC) supplies from Fisher Scientific (Fair Lawn, NJ); procine skin Type A gelatin (175 
bloom), Sephadex G50, pronase and glutaraldehyde (25\% in water) and all other chemicals from Sigma Chemical (St. Louis, MO); and ELISA kits from Hawaii Biotech (Aiea, HI). All chemicals were used as received.

\section{Preparation of PNP}

PNP were prepared using the desolvation method, as described previously ${ }^{15,16}$. The drug loading was $0.52 \pm 0.14 \%$ (mean $\pm \mathrm{SD}, \mathrm{n}=4$ ). The particle size, determined using a particle size analyzer (Nano-ZS90, Malvern), was $638 \pm 61 \mathrm{~nm}($ mean $\pm \mathrm{SD}, \mathrm{n}=4$ )

\section{Release of paclitaxel from PNP in vitro and in vivo}

For in vitro release, PNP (1 to $50 \mu \mathrm{g} / \mathrm{ml})$ was incubated with $20 \mathrm{ml}$ phosphate-buffered saline (PBS) at $37^{\circ} \mathrm{C}$. The in vivo drug release study was studied in tumor-free dogs (see below).

\section{Animal Protocols}

Two types of dogs were studied. Tumor-free beagle dogs were used to determine the in vivo drug release, systemic absorption, and pharmacokinetics in bladder tissues, under protocols approved by The Ohio State University Institutional Animal Care and Use Committee. Tumor-bearing pet dogs (various breeds) with pathologically confirmed transitional cell carcinoma (TCC) were used to determine the paclitaxel/PNP levels and the drug effects in tumors. These dogs were patients seen at The Ohio State University Veterinary Medicine Hospital and received intravesical therapy for disease management under protocols approved by the Veterinary Medicine Hospital Institute Review Board and with informed consents from owners. Animals received weekly intravesical PNP $(1 \mathrm{mg} / 20 \mathrm{ml}$ physiological saline) for three weeks. We previously showed that this dose would yield pharmacologically active drug concentrations in urothelium and lamina propria ${ }^{13,14}$.

\section{Studies of plasma, urine and bladder tissue pharmacokinetics in tumor-free dogs}

Following intubation, dogs were anesthetized with isofluorane inhalation. A jugular vein was catheterized for blood sample collection and a urethral catheter for administering drug solution and for collecting urine samples. All experiments were conducted between 7 and 10 am. The bladder was emptied and PNP was instilled into the bladder through the urethral catheter. After $2 \mathrm{hr}$, the bladder was emptied through the catheter. For the experiments that required tissue samples at time points beyond $8 \mathrm{hr}$, animals were allowed to wake from anesthesia and return to their housing units until the times when they were re-anesthetized. For tissue harvesting, the bladder was emptied and excised at different times (i.e., 4, 8, 24, $72,168 \mathrm{hr}$ ). Note, for example, the $4 \mathrm{hr}$ time point corresponded to $2 \mathrm{hr}$ after voiding the bladder. Euthanasia was accomplished by pentobarbital overdose. Tissue processing was as described previously 9,15 .

\section{Studies of drug concentrations of intravesical PNP in dog tumors}

Whenever medically feasible and with informed consent of owners, tumor specimens were obtained from pet dog patients before and/or immediately after the weekly treatments.

\section{Analysis of paclitaxel}

Samples were analyzed for free and total (sum of free plus PNP-bound) drug concentrations, as follows. An aliquot was incubated with the enzyme pronase $(1 \mathrm{mg} / \mathrm{ml})$ at $37^{\circ} \mathrm{C}$ for $1 \mathrm{hr}$ to digest the gelatin, and the resulting solution was analyzed for the total drug concentration. A second aliquot was centrifuged at $2500 \times \mathrm{g}$ for 30 min using a membrane with a MW cutoff of 10,000 Dalton, at room temperature. The filtrates were analyzed for the free drug concentrations. Paclitaxel was extracted and analyzed by two methods, i.e., HPLC for urine 
and drug release media samples that contained high drug levels and ELISA (competitive inhibition enzyme immunoassay) for plasma and tissue samples that contained lower drug levels, as described previously ${ }^{15,14}$. The lower limit of detection was $5 \mathrm{ng} / \mathrm{ml}$ for HPLC. ELISA detects all taxanes including paclitaxel and its metabolites; the lower detection limit was $0.1 \mathrm{ng} / \mathrm{ml}$ for $1 \mathrm{ml}$ of plasma, $2 \mathrm{ng} / \mathrm{g}$ for $50 \mathrm{mg}$ of bladder tissue, and $100 \mathrm{ng} / \mathrm{g}$ for $1 \mathrm{mg}$ of bladder tumor.

\section{Calculation of systemic drug absorption}

Calculation of systemic bioavailability of intravesical PNP requires the area-under-plasma concentration-time curve (AUC) and the plasma clearance of paclitaxel; bioavailability is the multiplication product of AUC and clearance. AUC was calculated using the linear trapezoidal rule. Due to the severe hypersensitivity of dogs to Cremophor, paclitaxel clearance in dogs has not been studied. Hence, the calculation used instead the drug clearance values in other species, i.e., mice, rats, and humans (see Table 1) 17-22.

\section{Statistical Analysis}

Comparison of values between groups was performed using two-tailed Student's $t$ tests. A value of $P<0.05$ was considered statistically significant.

\section{RESULTS}

\section{Solubility-limited drug release from PNP in vitro and in vivo}

Figure 1A shows the release of paclitaxel from PNP in PBS at $37^{\circ} \mathrm{C}$. The free paclitaxel concentration released into the medium increased only 2.5 -fold and reached a plateau level when the starting PNP concentration was increased 50-fold from 1 to $50 \mu \mathrm{g} / \mathrm{ml}$. This lack of dose-concentration proportionality indicates a nonlinear process that was rate-limited by a saturable property. The similarity between the plateau free concentration (between 1.3-1.4 $\mu \mathrm{g} / \mathrm{ml})$ and the aqueous solubility of paclitaxel $(\sim 1 \mu \mathrm{g} / \mathrm{ml})^{23}$ suggests that its release from PNP was rate-limited by drug dissolution.

Figure 1B shows the results of the in vivo drug release in tumor-free dogs $(\mathrm{n}=8)$. The urine results showed that over the 2-hr treatment duration, the urine volume increased $40 \%$ from $20 \mathrm{ml}$ to $28 \pm 3 \mathrm{ml}$ (mean $\pm \mathrm{SD}$ ), and the total paclitaxel concentrations in the urine (sum of free and PNP-bound drug) decreased about proportionally from $50 \mu \mathrm{g} / \mathrm{ml}$ in the dosing solution to $34 \pm 4 \mu \mathrm{g} / \mathrm{ml}$. In contrast, the free drug concentration remained nearly constant at $1.29 \pm 0.07 \mu \mathrm{g} / \mathrm{ml}$ (range, $1.18-1.36 \mu \mathrm{g} / \mathrm{ml}$ ), or nearly identical to the free plateau concentration obtained under in vitro release.

\section{Plasma pharmacokinetics of intravesical PNP in tumor-free dogs}

In dogs treated with intravesical PNP, paclitaxel was detectable in the plasma at all time points (up to $8 \mathrm{hr}$ after initiation of the 2-hr treatment); the average total concentrations were $0.54 \pm 0.25 \mathrm{ng} / \mathrm{ml}$ (mean $\pm \mathrm{SD}$; range, 0.1 to $1.72 \mathrm{ng} / \mathrm{ml} ; \mathrm{n}=8 \mathrm{dogs}$; Figure 1). Table 1 shows the AUC and systemic bioavailability at different time intervals; the bioavailability was about $0.60-0.84 \%$ of the administered dose during 0 to $4 \mathrm{hr}$ and $0.35-0.50 \%$ during $4-8$ $\mathrm{hr}$, with a cumulative value of $0.95-1.35 \%$ over $0-8 \mathrm{hr}$.

\section{Bladder tissue pharmacokinetics of intravescial PNP in tumor-free dogs}

Figure 3 shows the drug concentration-depth profiles at 4 to $168 \mathrm{hr}$ after initiation of the 2hr treatment ( 3 animals per time point). Total drug concentrations (sum of free and PNPbound concentrations) throughout the bladder were the highest at the first time point of $4 \mathrm{hr}$. The concentrations then declined with time and reached a relatively constant level that was 
sustained between 24 to $168 \mathrm{hr}$. The average total paclitaxel concentration of in tissue sections comprising the urothelium and lamina propria $(300 \mu \mathrm{m}$ depth from the inner surface of the bladder in dog) was $15.1 \mu \mathrm{g} / \mathrm{g}$ at $4 \mathrm{hr}$, and $0.18 \mu \mathrm{g} / \mathrm{g}$ after 1 week. The average drug concentrations in deeper tissues were $7.9 \mu \mathrm{g} / \mathrm{g}$ at $4 \mathrm{hr}$ and $0.24 \mu \mathrm{g} / \mathrm{g}$ after 1 week in the first $\mathrm{mm}$, and $4.4 \mu \mathrm{g} / \mathrm{g}$ at $4 \mathrm{hr}$ and $0.19 \mu \mathrm{g} / \mathrm{g}$ after 1 week for the entire bladder. This data indicates significant drug retention throughout the bladder for at least 1 week.

\section{Bladder tumor pharmacokinetics of intravesical PNP in pet dog patients}

A total of 13 tumor-bearing dogs were studied. One dog was found not to have TCC and was excluded. The remaining 12 dogs ( 8 females and 4 males) received three weekly treatments. Tumor biopsy samples were obtained from a total of $7 \mathrm{dogs}$ (all females), immediately after the first treatment, and again on day 7 and day 14 (samples taken before administration of second and third weekly doses). One dog was re-treated 3 months later again with three weekly treatments.

Figure 4 shows the drug concentrations in tumors. As expected, there were substantial interand intra-subject variations. The total paclitaxel concentrations showed a 13-fold range immediately after the first treatment, a 7-fold range on day 7 and a 20-fold range on day 14 . The time-dependent variations were observed for all animals, i.e., there were no animals with consistently high or consistently low drug concentrations, indicating the variations were random. Interestingly, the mean drug concentrations at the three time points remained relatively constant $(\sim 40 \mu \mathrm{g} / \mathrm{g})$ and the median concentrations were within $20-40 \%$ of the mean concentrations, indicating relatively constant drug exposure in individual animals upon repeated treatments.

A comparison of the results in Figures 3 and 4 shows a 360-fold higher average total paclitaxel concentration in bladder tumors compared to the concentrations in the urothelium of tumor-free dogs (i.e., the first tissue sections of $80 \mu \mathrm{m}$ thickness) one week after treatment. This indicates greater drug delivery/retention in tumor tissues.

\section{DISCUSSION}

Our major findings are as follows. First, the drug release data indicate a drug solubilitylimited release from PNP in vivo, yielding constant drug concentrations irrespective of changes in urine volume. This feature will minimize the substantial inter- and intra-subject variability in drug exposure due to residual urine at the time of dose administration and newly formed urine (e.g., 20-fold variations for MMC) ${ }^{4}$, thereby eliminate the need of dehydrating the patient and exhaustively emptying the bladder before treatment, and hence may improve the efficacy and enhance the ease of using intravesical therapy.

Second, only $\sim 1 \%$ of the intravesical PNP dose (1 mg paclitaxel-equivalent) was absorbed, yielding average plasma paclitaxel concentrations of $<2 \mathrm{ng} / \mathrm{ml}$. These levels are 1000-times below the threshold levels associated with clinical toxicity ${ }^{22}$, indicating intravesical PNP is not likely to result in systemic toxicity.

Third, the tissue pharmacokinetic data in tumor-free dogs indicate the average drug concentration in the urothelium and lamina propria at $4 \mathrm{hr}$ was at least 13-times the free drug concentration in the urine at $2 \mathrm{hr}$ and that a single dose of intravesical PNP yielded substantial drug levels sustained for at least 1 week. These results indicate preferential drug accumulation in tissues.

Fourth, compared to the concentrations previously observed with the Cremophor micelle formulation at $2 \mathrm{hr}$, the average drug concentrations derived from PNP at $4 \mathrm{hr}$ were 5.4- 
times higher in tissue sections comprising the urothelium plus lamina propria ( $300 \mu \mathrm{m}$ depth from the inner surface of the bladder in dog) and 4.4 times higher throughout the entire bladder, (15.1 vs 2.8 and $4.4 \mathrm{vs} 1.0 \mu \mathrm{g} / \mathrm{g}$, dose-adjusted to $1 \mathrm{mg} / 20 \mathrm{ml}$ ). These results indicate superior drug delivery from PNP.

Fifth, a comparison of the urine, tissue and plasma pharmacokinetics indicates the fate of the drug in tissues over time. For example, the sum of the drug amounts in all bladder tissue sections (data in Figure 3) equaled about $0.49 \%$ of the dose at $4 \mathrm{hr}$ and $0.16 \%$ at $8 \mathrm{hr}$, indicating a loss of $0.33 \%$ over the $4 \mathrm{hr}$ interval. This fraction is comparable to the sum of the amount of drug recovered in the urine over the same duration $(0.09 \%$ at $4 \mathrm{hr}$ and $0.12 \%$ at $8 \mathrm{hr}$, or a gain of $0.03 \%$ ) plus the amount of drug absorbed into the systemic circulation (a gain of $0.4 \%$ ). Hence, the drug in tissue was removed primarily by systemic absorption and, to a lesser extent, by diffusion back to urine.

Finally, we observed significant drug retention in bladder tissues from 24 to $168 \mathrm{hr}$. This is likely due to the drug binding, as we previously found a 100-to-1 ratio between the bound and free extracellular concentrations ${ }^{24}$. We further observed 360 -fold higher drug concentrations in tumors relative to normal tissues at the same tissue depth, indicating greater delivery/retention of PNP in tumors. One possibility is the loss of an intact urothelium in tumors resulting in enhanced drug penetration, as we previously observed for $\mathrm{MMC}^{25}$. Another possibility is preferential adsorption and/or trapping of PNP on/in tumors (e.g., papillary tumors in humans show a cauliflower-like structure, with grooves and creases), which would have resulted in higher and more sustained drug concentrations. The drug concentrations in bladder tissues (above $100 \mathrm{ng} / \mathrm{g}$ or $120 \mathrm{nM}$ at all tissue depths) are pharmacologically active. For example, the calculated AUC of paclitaxel from 2 to $168 \mathrm{hr}$ in the tumors located in urothelium and lamina propria of tumor-bearing dog bladders, derived from a single dose of intravesical PNP, is about $6660 \mu \mathrm{g} * \mathrm{hr} / \mathrm{g}$. This value is about 60-times higher than the pharmacologically active AUC of paclitaxel in tumor-bearing mice given an intravenous dose of paclitaxel dissolved in Cremophor/ethanol or formulated as albumincoated nanoparticles (respective AUC of 110 and $145 \mu \mathrm{g} * \mathrm{hr} / \mathrm{g}$ for a $20 \mathrm{mg} / \mathrm{kg}$ dose ${ }^{26}$ ). Based on these tissue/tumor pharmacokinetic data, we propose a single intravesical PNP dose would yield pharmacologically active drug levels in urothelium and lamina propria sustained for 1 week or longer.

In summary, intravesical PNP shows the desired properties for intravesical therapy, i.e., favorable bladder tissue/tumor targeting, penetration and retention properties, and low systemic absorption. We propose that clinical evaluation of intravesical PNP is warranted, and are pursuing computational studies to integrate the pharmacokinetic data described herein and our previously reported pharmacodynamic data of paclitaxel in human bladder tumor histocultures ${ }^{27}$, for the purpose of defining the clinical trial design (i.e., dose, dosing frequency, number of patients, statistical power). We used a similar computational approach was successfully applied to design a phase III trial of intravesical mitomycin C, where the clinical outcome closely aligns with the computation-predicted outcome ${ }^{28,29}$.

\section{Acknowledgments}

This work was supported in part by research grants R43 CA107743 and R44 CA107743 from the National Cancer Institute, NIH, DHHS.

\section{References}

1. Smith JA Jr, Labasky RF, Cockett AT, et al. Bladder cancer clinical guidelines panel summary report on the management of nonmuscle invasive bladder cancer (stages Ta, T1 and TIS). The American Urological Association. J Urol. 1999; 162:1697. [PubMed: 10524909] 
2. Wientjes MG, Dalton JT, Badalament RA, et al. A method to study drug concentration-depth profiles in tissues: mitomycin C in dog bladder wall. Pharm Res. 1991; 8:168. [PubMed: 1902562]

3. Wientjes MG, Dalton JT, Badalament RA, et al. Bladder wall penetration of intravesical mitomycin C in dogs. Cancer Res. 1991; 51:4347. [PubMed: 1907883]

4. Dalton JT, Wientjes MG, Badalament RA, et al. Pharmacokinetics of intravesical mitomycin C in superficial bladder cancer patients. Cancer Res. 1991; 51:5144. [PubMed: 1913640]

5. Huang GJ, Hamilton AS, Lo M, et al. Predictors of intravesical therapy for nonmuscle invasive bladder cancer: results from the surveillance, epidemiology and end results program 2003 patterns of care project. J Urol. 2008; 180:520. [PubMed: 18550088]

6. Whelan DP. Words of wisdom. Re: predictors of intravesical therapy for nonmuscle invasive bladder cancer: results from the Surveillance, Epidemiology and End Results Programme (SEER) 2003 Patterns of Care Project. Eur Urol. 2008; 54:1443. [PubMed: 19189439]

7. Kugler A, Haschemi R, Zoller G, et al. In vitro investigations of new therapeutic agents on bladder tumor cell lines. Urol Res. 1997; 25:247. [PubMed: 9286032]

8. Roth BJ. Preliminary experience with paclitaxel in advanced bladder cancer. Semin Oncol. 1995; 22:1. [PubMed: 7541150]

9. Song D, Wientjes MG, Au JLS. Bladder tissue pharmacokinetics of intravesical taxol. Cancer Chemother Pharmacol. 1997; 40:285. [PubMed: 9225946]

10. Kuh HJ, Jang SH, Wientjes MG, et al. Computational model of intracellular pharmacokinetics of paclitaxel. J Pharmacol Exp Ther. 2000; 293:761. [PubMed: 10869374]

11. Cote RJ, Esrig D, Groshen S, et al. p53 and treatment of bladder cancer. Nature. 1997; 385:123. [PubMed: 8990112]

12. Woods CM, Zhu J, McQueney PA, et al. Taxol-induced mitotic block triggers rapid onset of a p53independent apoptotic pathway. Mol Med. 1995; 1:506. [PubMed: 8529117]

13. Knemeyer I, Wientjes MG, Au JL. Cremophor reduces paclitaxel penetration into bladder wall during intravesical treatment. Cancer Chemother Pharmacol. 1999; 44:241. [PubMed: 10453726]

14. Chen D, Song D, Wientjes MG, et al. Effect of dimethyl sulfoxide on bladder tissue penetration of intravesical Paclitaxel. Clin Cancer Res. 2003; 9:363. [PubMed: 12538489]

15. Lu Z, Yeh TK, Tsai M, et al. Paclitaxel-loaded gelatin nanoparticles for intravesical bladder cancer therapy. Clin Cancer Res. 2004; 10:7677. [PubMed: 15570001]

16. Tsai M, Lu Z, Wang J, et al. Effects of Carrier on Disposition and Antitumor Activity of Intraperitoneal Paclitaxel. Pharm Res. 2007

17. Eiseman JL, Eddington ND, Leslie J, et al. Plasma pharmacokinetics and tidssue distribution of paclitaxel in CD2F1 mice. Cancer Chemother Pharmacol. 1994; 6:465. [PubMed: 7923556]

18. Sparreboom A, van Tellingen O, Nooijen W, et al. Nonlinear pharmacokinetics of paclitaxel in mice results from thepharmaceutical vehicle cremophor EL. Cancer Res. 1996; 56:2112. [PubMed: 8616858]

19. He L, Wang GL, Zhang Q. An alternative paclitaxel microemulsion formulation: hypersensitivity evaluation and pharmacokinetic profile. Int J Pharm. 2003; 250:45. [PubMed: 12480272]

20. Zhang C, Qu G, Sun Y, et al. Pharmacokinetics, biodistribution, efficacy and safety of N-octyl-Osulfate chitosan micelles loaded with paclitaxel. BIOMATERIALS. 2008; 29:1233. [PubMed: 18093646]

21. Sparreboom A, Scripture CD, Trieu V, et al. Comparative preclinical and clinical pharmacokinetics of a cremophor-free, nanoparticle albumin-bound paclitaxel (ABI-007) and paclitaxel formulated in Cremophor (Taxol). Clin Cancer Res. 2005; 11:4136. [PubMed: 15930349]

22. Huizing MT, Keung AC, Rosing H, et al. Pharmacokinetics of paclitaxel and metabolites in a randomized comparative study in platinum-pretreated ovarian cancer patients. J Clin Oncol. 1993; 11:2127. [PubMed: 7901342]

23. Liggins RT, Hunter WL, Burt HM. Solid-state characterization of paclitaxel. J Pharm Sci. 1997; 86:1458. [PubMed: 9423162]

24. Kuh HJ, Jang SH, Wientjes MG, et al. Determinants of paclitaxel penetration and accumulation in human solid tumor. J Pharmacol Exp Ther. 1999; 290:871. [PubMed: 10411604] 
25. Gao X, Au JL, Badalament RA, et al. Bladder tissue uptake of mitomycin C during intravesical therapy is linear with drug concentration in urine. Clin Cancer Res. 1998; 4:139. [PubMed: 9516962]

26. Desai N, Trieu V, Yao Z, et al. Increased antitumor activity, intratumor paclitaxel concentrations, and endothelial cell transport of cremophor-free, albumin-bound paclitaxel, ABI-007, compared with cremophor-based paclitaxel. Clin Cancer Res. 2006; 12:1317. [PubMed: 16489089]

27. Au JL, Kalns J, Gan Y, et al. Pharmacologic effects of paclitaxel in human bladder tumors. Cancer Chemother Pharmacol. 1997; 41:69. [PubMed: 9443616]

28. Au JL, Badalament RA, Wientjes MG, et al. Methods to improve efficacy of intravesical mitomycin C: results of a randomized phase III trial. J Natl Cancer Inst. 2001; 93:597. [PubMed: 11309436]

29. Au JL, Badalament RA, Wientjes MG, et al. Optimized intravesical mitomycin C treatment for superficial bladder cancer: long-term follow-up. J Urol. 2006; 175:268.

\section{Abbreviations used are}

AUC area-under-concentration-time curve

BCG Bacillus Calmette-Guérin

DMSO dimethyl sulfoxide

ELISA competitive inhibition enzyme immunoassay

HPLC high performance liquid chromatography

MMC mitomycin C

PBS phosphate-buffered saline

PNP paclitaxel gelatin nanoparticles

TCC transitional cell carcinoma 
A. In PBS

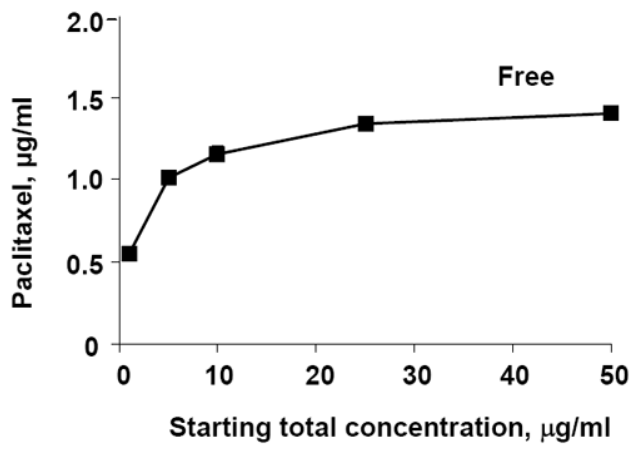

B. In urine of tumor-free dogs

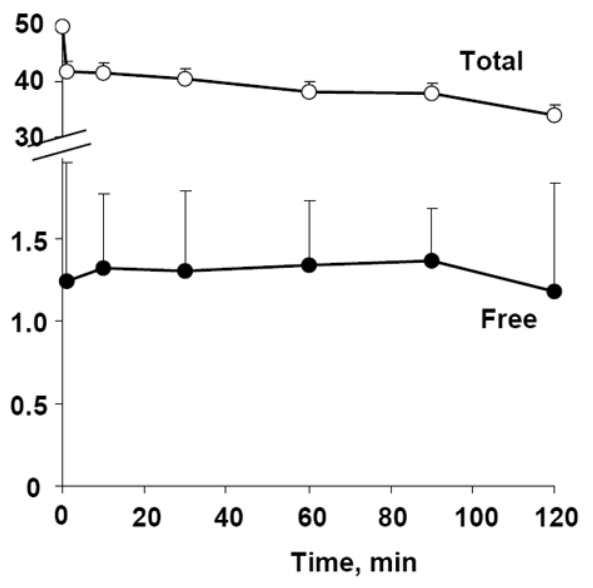

Figure 1. Release of paclitaxel from PNP

(A) In vitro release of paclitaxel from PNP (1 to $50 \mu \mathrm{g} / \mathrm{ml}$ paclitaxel-equivalent) in PBS. Data are mean $+1 \mathrm{SD}(\mathrm{n}=3)$. Note that SD are smaller than symbols. (B) Release of paclitaxel in urine of tumor-free dogs given a dose of intravesical PNP $(1 \mathrm{mg} / 20 \mathrm{ml}$ paclitaxel-equivalent). Note the break in the y axis. Over the 2-hr treatment, the volume of urine increased from 20 to $28 \mathrm{ml}$ and the total concentration (PNP-bound and free drug) declined from 50 to $34 \mu \mathrm{g} / \mathrm{ml}$, whereas the free paclitaxel concentrations remained relatively constant at 1.18-1.36 $\mu \mathrm{g} / \mathrm{ml}$. Data are mean + 1 SD $(n=8)$. 


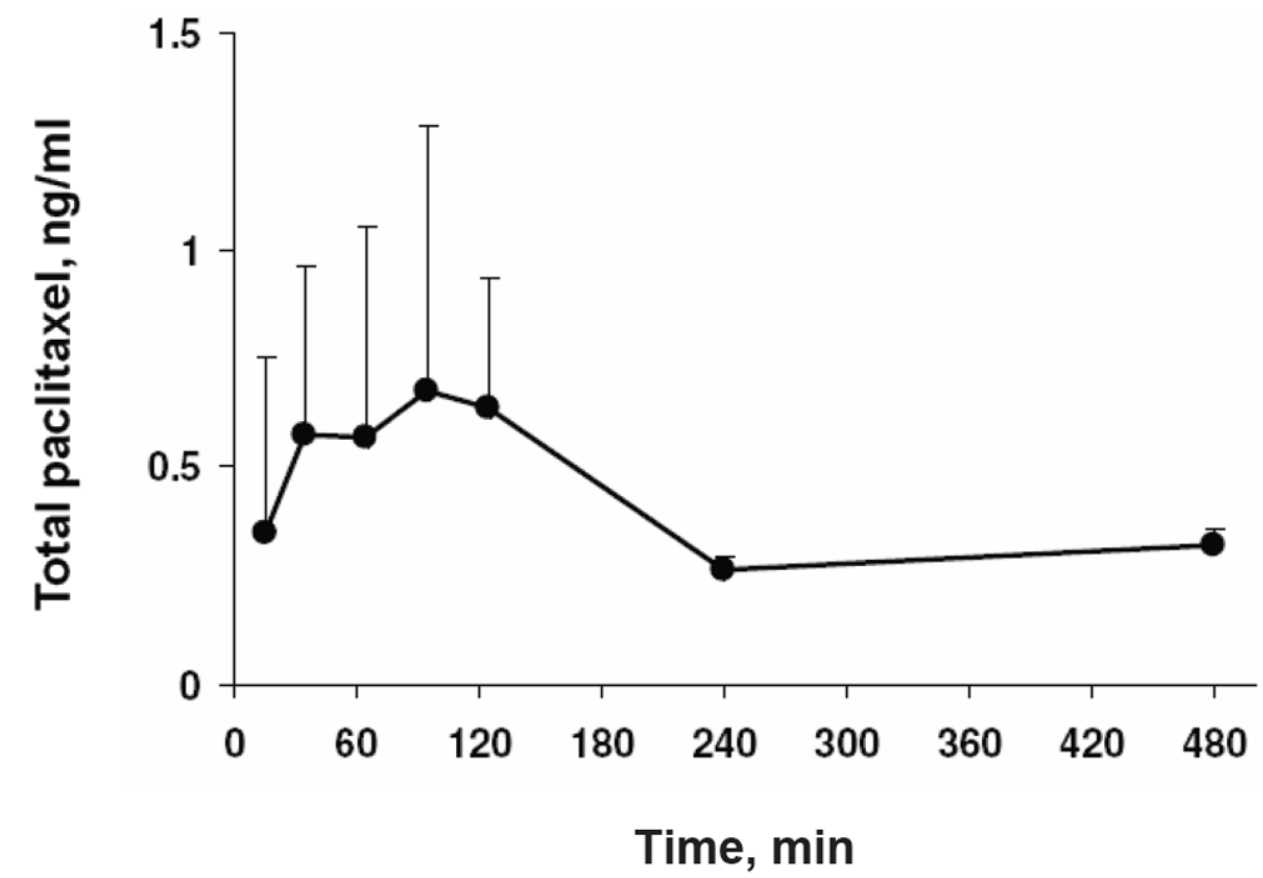

Figure 2. Plasma pharmacokinetics of paclitaxel in tumor-free dogs given intravesical PNP Animals were given a single dose of intravesical PNP ( $1 \mathrm{mg} / 20 \mathrm{ml}$ paclitaxel-equivalent). Plasma samples were analyzed by ELISA for the total paclitaxel concentrations. Data are mean +1 SD (n=3 at 240 and $480 \mathrm{~min}, \mathrm{n}=8$ for other times). Some SD are smaller than symbols. 


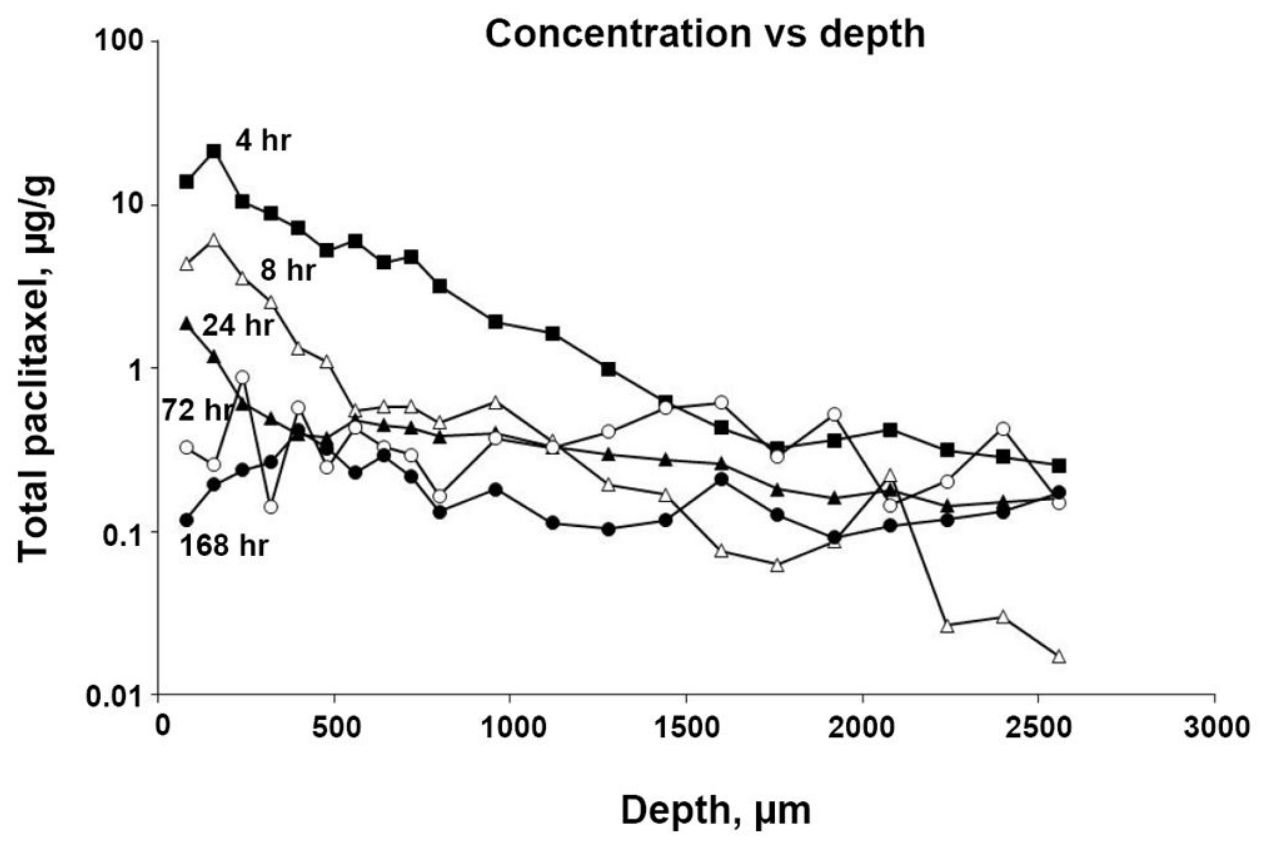

Figure 3. Bladder tissue pharmacokinetics of paclitaxel in tumor-free dogs given intravesical PNP

Animals were given a single dose of intravesical PNP (1 mg/20 ml paclitaxel-equivalent). Bladders were removed at predetermined times, frozen and cryo-sectioned. The first two sections $(40 \mu \mathrm{m})$ were discarded to avoid contamination of tissue by urine that contained high drug concentrations. Drug concentrations in tissue sections were analyzed by ELISA. Total paclitaxel concentrations as a function of tissue depth, at five time points, i.e., 4, 8, 24, 72 and $168 \mathrm{hr}$ after initiation of the 2-hr treatment. Data are mean values ( $\mathrm{n}=3$ per group). The average SD was $68 \%$ (range 6-180\%, median: 61\%) of the mean values (not shown). 


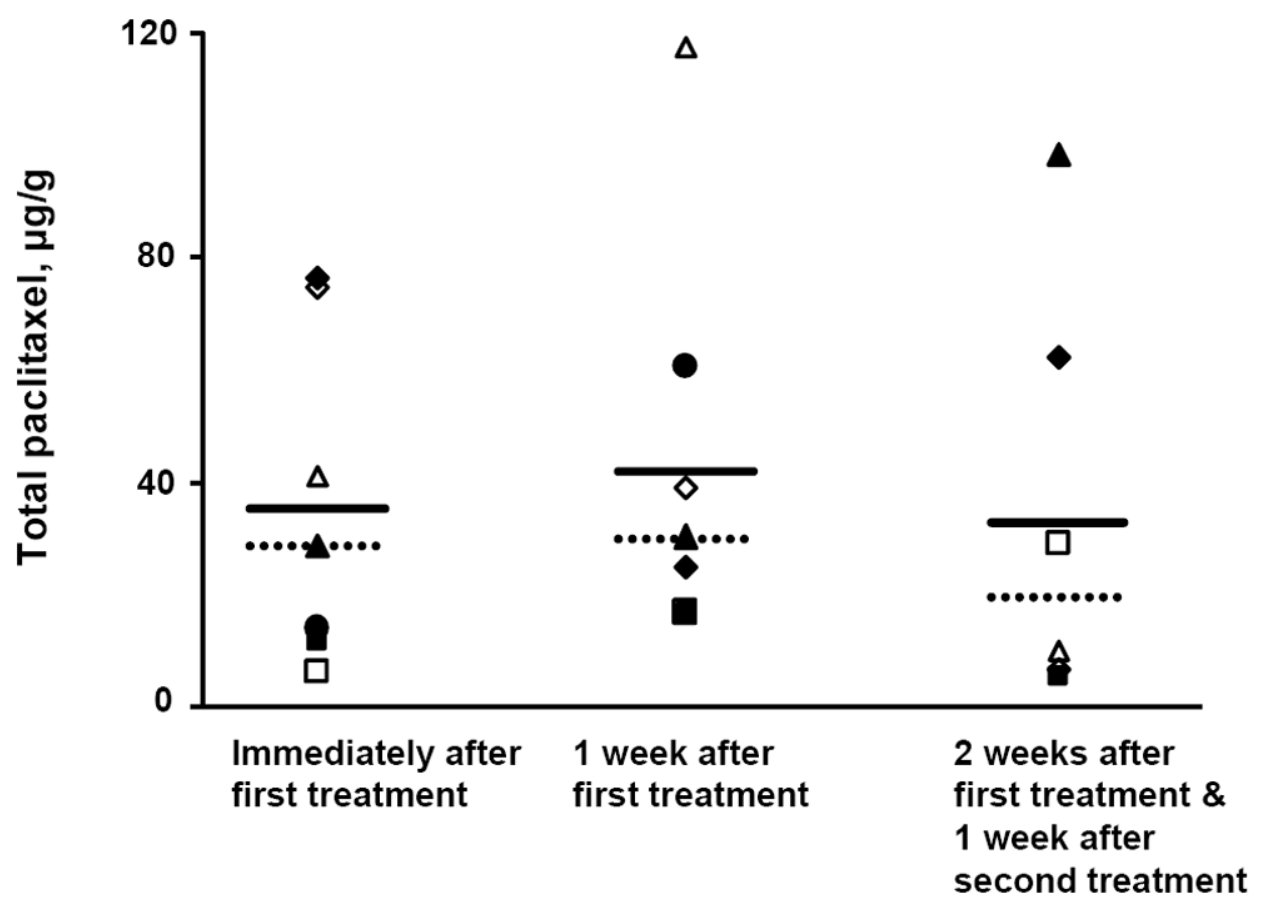

Figure 4. Bladder tumor concentrations of paclitaxel in dogs with naturally occurring tumors after intravesical PNP

Tumor-bearing pet dogs were treated with three weekly doses of intravesical PNP (1 mg/20 $\mathrm{ml}$ paclitaxel-equivalent). Tumor samples were obtained immediately after the first treatment, and again on day 7 and day 14. The day 7 and 14 samples were taken before animals received their second and third weekly treatments. Hence, the day 7 samples were obtained 1 week after the first treatment, and the day 14 samples were obtained 2 weeks after the first treatment and 1 week after the second treatment. Drug concentrations, measured by ELISA, were $36.3 \pm 29.4 \mu \mathrm{g} / \mathrm{g}$ at $2 \mathrm{hr}$ after initiation of treatment (mean $\pm \mathrm{SD}$; median was $28.8 \mu \mathrm{g} / \mathrm{g}$; range was $6.4-76.6 \mu \mathrm{g} / \mathrm{g} ; \mathrm{n}=7$ ), $43.9 \pm 35.9 \mu \mathrm{g} / \mathrm{g}$ at 1 week after initiation of the first treatment (mean \pm SD; median was $30.3 \mu \mathrm{g} / \mathrm{g}$; range was $16.8-117.6 \mu \mathrm{g}$ / $\mathrm{g} ; \mathrm{n}=6$ ), and $35.5 \pm 37.8 \mu \mathrm{g} / \mathrm{g}$ at 2 weeks after initiation of the first treatment and 1 week after the second treatment (mean $\pm \mathrm{SD}$; median was $19.7 \mu \mathrm{g} / \mathrm{g}$; range was 5.5-98.8 $\mu \mathrm{g} / \mathrm{g}$; $\mathrm{n}=6$ ). Solid lines: mean values. Dotted lines: median values. 


\section{Table 1}

Systemic bioavailability of paclitaxel in tumor-free dogs given an intravesical dose of PNP (1 mg/20 ml).

\begin{tabular}{|c|c|c|c|}
\hline \multirow[t]{2}{*}{$\begin{array}{l}\text { Literature data on paclitaxel clearance in other } \\
\text { species, median (range), } \mathrm{l} / \mathrm{hr} * \mathrm{~kg}\end{array}$} & \multicolumn{3}{|c|}{$\begin{array}{l}\text { Calculated systemic bioavailability in dogs using clearance values in other } \\
\text { species }(\%)\end{array}$} \\
\hline & $0-4 \mathrm{hr}$ & $4-8 \mathrm{hr}$ & $0-8 \mathrm{hr}$ \\
\hline Mice: $0.301(0.15-0.56)^{17,18}$ & 0.60 & 0.35 & 0.95 \\
\hline Rats: $0.366(0.243-0.837)^{19-21}$ & 0.73 & 0.43 & 1.16 \\
\hline Humans: $0.430(0.296-0.577)^{22}$ & 0.84 & 0.50 & 1.35 \\
\hline
\end{tabular}

Systemic bioavailability in dogs was calculated using the plasma data shown in Figure 2 and the median values of the clearance of paclitaxel (formulated in Cremophor micelles) in rodents and humans. This was necessary because the clearance in dogs has not been studied due to the severe Cremophor hypersensitivity in this species. The AUC in dogs was $119.2 \mathrm{ng} * \mathrm{~min} / \mathrm{ml}$ from 0-4 hr, $70.3 \mathrm{ng} * \mathrm{~min} / \mathrm{ml}$ from 4-8 hr, and 189.5 $\mathrm{ng} * \mathrm{~min} / \mathrm{ml}$ from $0-8 \mathrm{hr}$. 